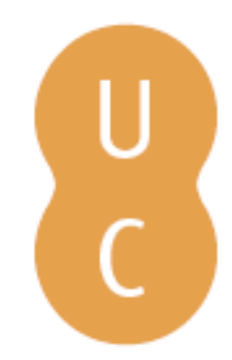

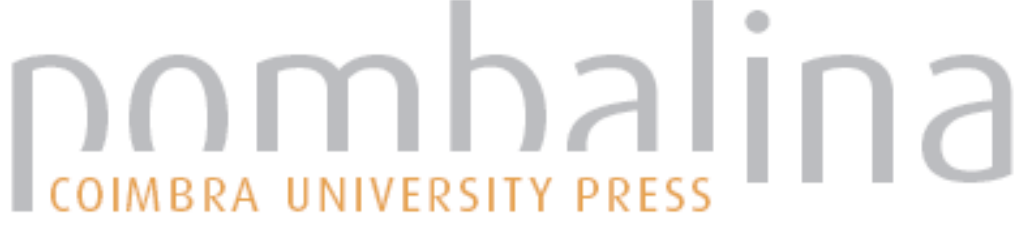

\section{O método em Pedro da Fonseca e no curso conimbricense}

\author{
Autor(es): $\quad$ Coxito, Amândio
}

Publicado por: Imprensa da Universidade de Coimbra

URL

persistente: URI:http://hdl.handle.net/10316.2/32226

DOI: $\quad$ DOI:http://dx.doi.org/10.14195/978-989-26-0361-2_2

Accessed : $\quad$ 26-Apr-2023 15:34:52

A navegação consulta e descarregamento dos títulos inseridos nas Bibliotecas Digitais UC Digitalis, UC Pombalina e UC Impactum, pressupõem a aceitação plena e sem reservas dos Termos e Condições de Uso destas Bibliotecas Digitais, disponíveis em https://digitalis.uc.pt/pt-pt/termos.

Conforme exposto nos referidos Termos e Condições de Uso, o descarregamento de títulos de acesso restrito requer uma licença válida de autorização devendo o utilizador aceder ao(s) documento(s) a partir de um endereço de IP da instituição detentora da supramencionada licença.

Ao utilizador é apenas permitido o descarregamento para uso pessoal, pelo que o emprego do(s) título(s) descarregado(s) para outro fim, designadamente comercial, carece de autorização do respetivo autor ou editor da obra.

Na medida em que todas as obras da UC Digitalis se encontram protegidas pelo Código do Direito de Autor e Direitos Conexos e demais legislação aplicável, toda a cópia, parcial ou total, deste documento, nos casos em que é legalmente admitida, deverá conter ou fazer-se acompanhar por este aviso.

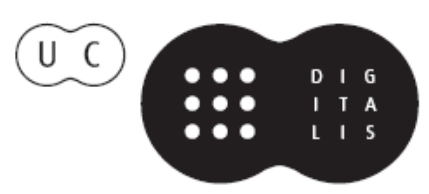


Diogo Ferrer

Coordenação

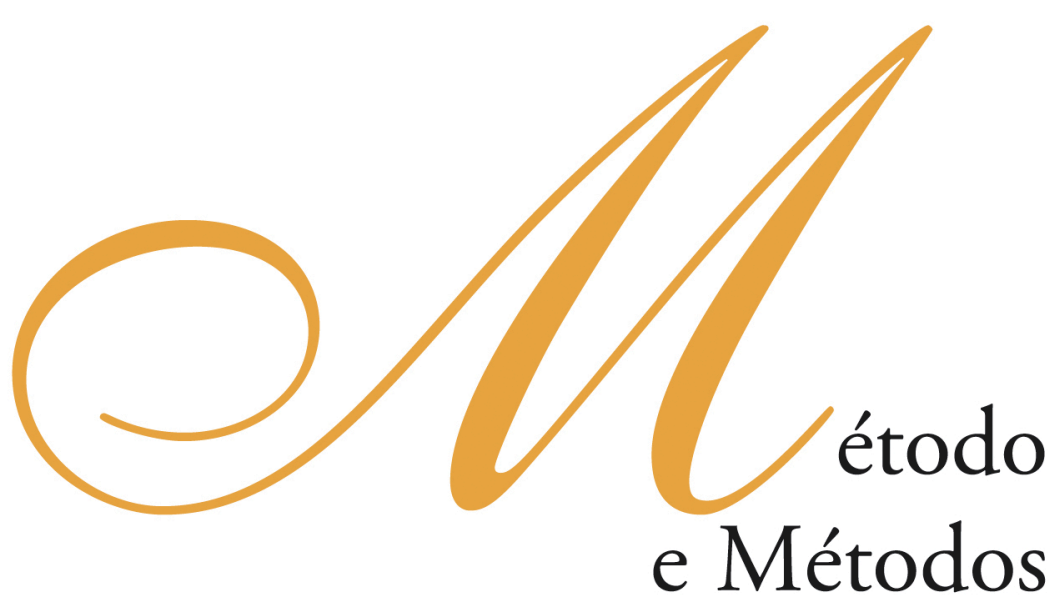

do Pensamento Filosófico 


\section{COORDENAÇÃO EDITORIAL \\ Imprensa da Universidade de Coimbra}

URL: http//www.imp.uc.pt

\section{CONCEPÇÃO GRÁFICA}

António Barros

PRÉ-IMPRESSÃO

Victor Hugo Fernandes

EXECUÇÃO GRÁFICA

Inova - Artes gráficas

ISBN

989-8074-02-7

DEPÓSITO LEGAL

$257236 / 07$

(C) Março 2007, Imprensa da Universidade de Coimbra

OBRA PUBLICADA COM O APOIO DE:

Centro de Estudos Clássicos e Humanísticos

FCT Fundação para a Ciência e a Tecnologia MINISTÉRIO DA CIÊNCIA E DA TECNOLOGIA 
Diogo Ferrer

Coordenação

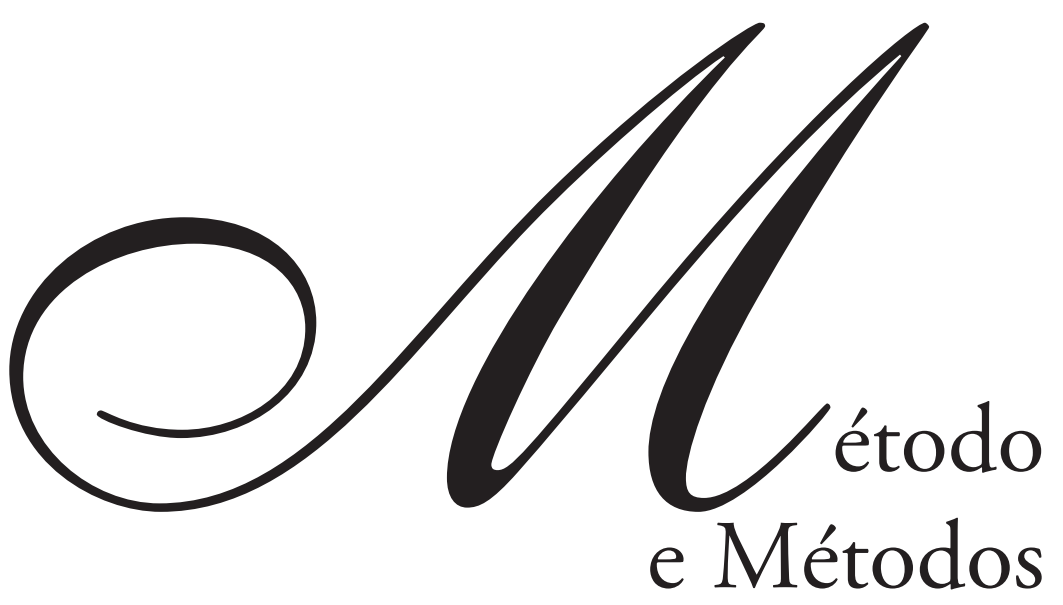

do Pensamento Filosófico

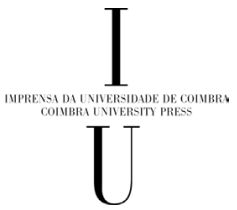

- COIMBRA 2007 



\section{Amândio Coxito \\ Universidade de Coimbra}

\section{O Método em Pedro da Fonseca e no Curso Conimbricense}

A publicação do Discurso do Método de Descartes costuma considerar-se uma viragem na especulação filosófica ocidental. Contudo, havia já pelo menos um século que o problema do método preocupava activamente o pensamento europeu, a ponto de palavras como "via», «ratio», "ordo», «modus» e "methodus» aparecerem profusamente em títulos de publicações renascentistas - especialmente de natureza didáctica - ainda que não fosse muito claro nessa época o sentido do termo "methodus e de outros afins. De qualquer modo, com as suas preocupações de ordem e de método os autores renascentistas não pretendiam apenas que as suas obras se apresentassem metodicamente redigidas, pois eles forneciam também uma série de normas tendo em vista a investigação e o ensino no âmbito das diferentes artes e ciências. É este facto que, quanto ao essencial, caracteriza o novo desenvolvimento da lógica da época, ainda que não se reduzisse esta disciplina a pura metodologia.

Sobre a metodologia renascentista, pode dizer-se, esquematicamente, que ela recai sobre o modo como as artes e as ciências foram descobertas, como são apresentadas ou «dispostas» e como são demonstradas. Dividem-se, assim, em duas grandes categorias as discussões sobre o método, consoante elas incidam sobre o que podemos designar por "método artístico» e por "método científico", fornecendo o primeiro destes métodos as normas de exposição doutrinal do já sabido, e o segundo as normas de descoberta de novos 
conteúdos e as da sua demonstração. Estas duas categorias proporcionam o esquema adequado para o estudo da metodologia renascentista. É importante, porém, sublinhar que as várias espécies dos métodos "artístico» e "científico» não são designadas univocamente pelos diversos autores, o que vem originar dificuldades na sua interpretação dentro do esquema mencionado.

Por outro lado, deve considerar-se que a metodologia do Renascimento tem origem em duas fontes fundamentais: a primeira é a dos Segundos Analíticos, que estudam a demonstração científica, segundo a qual a ciência é estabelecida dedutivamente com base em certos postulados irredutíveis que em si mesmos não é possível demonstrarem-se, mas que são apreendidos por intuição; a segunda é a dos Tópicos, que estudam o silogismo dialéctico como instrumento do conhecimento provável.

A grande dificuldade estava em conciliar estas duas tradições doutrinais. E o certo é que na literatura lógica renascentista que incluísse uma secção sobre o método os autores mais vinculados à tradição aristotélica sentiam-se compelidos a defender as suas doutrinas na linha que reputavam como mais estritamente peripatética, isto é, com base na teoria da demonstração científica dos Segundos Analíticos. Outros autores, porém, acentuavam a doutrina dos Tópicos de Aristóteles e de Cícero, bem como a dos comentários que Boécio realizou sobre a obra deste último, segundo a orientação designada por «retórico-ciceroniana». Encontram-se entre estes últimos autores os "dialécticos" renascentistas que, imbuídos, em geral, de uma atitude probabilista, se serviam do raciocínio dialéctico como instrumento de discussão de problemas nos domínios da pedagogia, da moral e da política, onde não é possível obterem-se conclusões apodícticas.

Ora, Pedro da Fonseca propõe-se conciliar as duas tradições mencionadas. De facto, o aspecto mais característico da sua metodologia é a ampla investigação da lógica tópica, sem, no entanto, pôr em causa o conceito aristotélico de ciência como demonstração do necessário. Ele confronta a demonstração científica com o raciocínio dialéctico, salientando que a finalidade da demonstração é produzir ciência e a do silogismo dialéctico 
é gerar opinião. Mas são conciliadas por Fonseca as duas vertentes quando escreve que o método tópico da «inuentio» pressupõe que o âmbito dos lugares dialécticos «é comum àquele que persuade com argumentos prováveis e àquele que infere por demonstração». Por isso, a tópica não constitui uma forma inferior de lógica, mas é solidária da analítica, dado que uma e outra se servem do mesmo método de pesquisa de argumentos (o método inventivo), quer eles sejam prováveis, quer necessários.

Mas a respeito de Fonseca não é presentemente necessário embrenharmo-nos em considerações sobre a doutrina dos lugares dialécticos. Basta apenas referir que - juntamente com a doutrina dos Analíticos — ela está presente nas concepções do método "científico" e do método "artístico". Não deve, porém, esquecer-se que as ideias sobre o método nesta época recebem também de outras fontes a sua inspiração, nomeadamente de Galeno (que com Aristóteles teve um papel decisivo na formulação do método científico), dos comentadores gregos e latinos do Perípato e das concepções antigas do método geométrico da análise e da síntese; e tudo isto em simbiose com elementos estóicos e neoplatónicos.

Como foi referido, na tradição aristotélica o método científico por excelência é a dedução. Contudo, aceitando que um método científico é sobretudo um esforço de aquisição ou uma passagem da simples probabilidade à certeza, temos de concluir que os Segundos Analíticos não realizam esse ideal. É por isso que Fonseca estuda ainda vários outros métodos de pesquisa científica, designadamente a definição, a divisão e a colecção. No entanto, após ele ter caracterizado estes métodos, apercebemo-nos de que o filósofo de Coimbra se limitou a repetir o que sobre a investigação científica já havia sido dito pelos seus antecessores. Neste âmbito, Fonseca não é de modo algum um precursor das concepções metodológicas do início da época moderna.

Sendo assim, o que sobressai neste nosso pensador é a concepção do método "artístico", por ele designado por "ordem da doutrina» (ou "ordem do ensino»). De um modo genérico, consiste o ordem do ensino em principiar 
por conhecimentos que pela sua natureza ou pela condição intelectual das pessoas a quem eles se destinam oferecem maiores vantagens em serem expostos em primeiro lugar. Por isso, é mais conveniente principiar por conhecimentos que sejam requeridos para a compreensão dos outros e, tanto quanto possível, dos mais fáceis para os mais difíceis. Contudo, neste processo não há uma ordem rígida. Consoante as conveniências, observar-se-á umas vezes a ordem da geração (que progride dos efeitos para as causas ou das partes integrantes para o todo), outras vezes a ordem da perfeição (inversa da anterior), outras vezes ainda as duas conjuntamente. As preocupações pedagógicas de Fonseca vão ao ponto de sugerir em que casos deve adoptar-se um ou outro desses procedimentos. Assim, aqueles que desejarem filosofar sem mestre (os autodidactas), penetrando pelos próprios meios nos assuntos mais difíceis, deverão progredir do particular para o geral e do todo para as partes, segundo as ordens da análise e da colecção. Principia esta via (que é também a mais adequada à constituição da ciência) pelos assuntos mais conhecidos para nós e, por isso, mais próximos da sensação. Mas o método ideal é seguir a ordem que a natureza realiza na produção das coisas, progredindo das partes integrantes para o todo e do mais universal para o menos universal (ordens da síntese e da divisão). É este o método adoptado por quem expõe um assunto que já conhece perfeitamente. Há casos, porém, em que esses princípios não são susceptíveis de aplicação. Nestas circunstâncias, aconselha Fonseca a que se obedeça à ordem da dignidade, que ele próprio põe em prática, por exemplo, quando expõe as figuras do silogismo e as formas da argumentação. Por último, em casos especiais será necessário usar um procedimento arbitrário, designadamente quando não existe uma gradação segundo a dificuldade ou a generalidade dos materiais de ensino que possibilitem definir uma ordem de prioridades.

Estamos, assim, muito distantes da monometodologia simplista de Petrus Ramus, tão criticada na época, o que significa por parte de Fonseca um 
pragmatismo pedagógico em consonância com os ideais do Ratio studiorum dos Jesuítas.

Vamos agora aludir ao Curso Conimbricense. Além da dedução, não há referências neste Curso aos métodos científicos estudados por Fonseca. Contudo, não é menosprezada a problemática do método «artístico». Mas, contrariamente ao que se verifica em Fonseca, ela não é explanada em qualquer dos comentários dos Conimbricenses. Existem apenas referências esporádicas a esse método - que, tal como em Fonseca, é designado por «método de doutrina» - isto é, o método de exposição e ordenação dos materiais de ensino, em que, relativamente a Fonseca, deparamos com uma maior uniformidade dos processos metodológicos, com a opção por um princípio de economia segundo o qual na transmissão do saber deve sempre progredir-se do mais geral para o mais particular, evitando-se, assim, a repetição constante dos mesmos dados. Inspira-se este princípio num passo de As Partes dos Animais de Aristóteles, onde pode ler-se que, se no estudo dos animais principiássemos por considerar cada um deles individualmente, "ver-nos-1́amos forçados a realizar frequentes repetições desnecessárias todas as vezes que existissem as suas características noutros animais de espécie diferente».

À falta de explanação doutrinal desta metodologia por parte dos Conimbricenses, ela deve ser estudada nas suas aplicações em concreto à elaboração do Curso, no que respeita ao modo de estruturação dos diversos tratados e das suas partes e ao modo de discussão dos vários problemas. Essas concretizações estão bem patentes, por exemplo, nas extensas introduções aos comentários sobre a Física e sobre a Lógica, em que verificamos estarem dispostos os assuntos da seguinte forma: definição do género de saber englobante da disciplina em causa (definição de filosofia, de ciência, de arte); divisão desse género nas suas espécies (classificação das artes ou ciências em reais e sermocinais, especulativas e práticas, superiores e 
inferiores); subdivisão de cada uma destas espécies nos seus subordinados (por exemplo, subdivisão das ciências especulativas em Metafísica, Física

e Matemática); definição da disciplina que vai ser objecto de estudo e sua integração no género a que pertence; divisão da disciplina nos seus aspectos fundamentais (por exemplo, da Dialéctica em «docens» e «utens»); delimitação do objecto da disciplina; determinação do lugar da disciplina entre as outras da sua espécie. Todo este procedimento é, portanto, orientado pelo esquema da definição e da divisão. E os conceitos a definir remetem para um todo indistinto, para um universal confuso; e é com base nessa indistinção inicial que são integrados os diversos elementos.

Poderíamos ainda referir outros factos comprovativos da mesma metodologia, sendo os de maior relevância os seguintes: $10^{\circ}$ ) as introduções gerais a todos os comentários, entre as quais as dos comentários à Física e à Lógica podem considerar-se, em certa medida, verdadeiras introduções a toda a filosofia; $2^{\circ}$ ) as sínteses que antecedem em todos os comentários os diversos livros que os constituem e ainda, nos comentários à Lógica, as sumas que precedem a explanação de cada capítulo: umas e outras são um modelo de clareza e concisão, colocando perante o leitor o essencial dos capítulos e dos livros de Aristóteles; $3 .^{\circ}$ ) a apresentação do texto do Perípato antes de cada capítulo ao centro da página (traduzido para latim nas edições portuguesas e expresso também no original grego nas edições estrangeiras), envolvido pela respectiva "explanatio» ou esclarecimento, em linhas gerais, da doutrina aristotélica presente no texto (são excepções a esta regra os comentários aos Meteoros, aos Pequenos Naturais e à Ética a Nicómaco; mas este procedimento é ainda motivado por objectivos pedagógicos, concretamente - como se lê nos comentários aos Meteoros - por razões de concisão, "necessária para os ouvintes de Filosofia, que devem realizar o seu currículo de Artes no tempo previamente determinado»; $\left.4^{\circ} .^{\circ}\right)$ a estrutura da "quaestio", progredindo mediante posições, contraposições, dúvidas e conclusão final, segundo um processo dinâmico e progressivo de transmissão de conhecimentos. Obedecem todos estes procedimentos ao 
princípio antes mencionado de que - como está escrito nos comentários à Física — «na transmissão do saber deve existir uma determinada ordem, estudando em primeiro lugar os assuntos mais gerais e expondo seguidamente os aspectos parcelares uns após outros e no momento adequado"; 5. ${ }^{\circ}$ ) em cada "articulus», a disposição ordenada, que principia pelos aspectos mais genéricos, apresentando os dados históricos e esclarecimentos de questões de terminologia, quando necessário, a que se segue a enumeração dos argumentos que possam apoiar ou infirmar a doutrina em discussão, com uma síntese final.

A respeito do "método de doutrina», transparece com evidência de tudo o que ficou dito que as concepções metodológicas de Pedro da Fonseca e dos Conimbricenses revelam uma clara compreensão do problema da pedagogia das artes e das ciências. Aliás, neste ponto eles exprimem uma atitude que era comum a todos os dialécticos da sua época e da imediatamente anterior. Já Rodolfo Agrícola escrevera no século XV que a finalidade da dialéctica é "ensinar aos ouvintes determinados assuntos», tendo em vista a adesão dos seus espíritos. E esta mesma ideia é sugerida pela própria definição da dialéctica como "facultas disserendi», pois o termo "disserendi» veio a ser associado a ensino, a ponto de Piscator poder escrever que "disserere» é o mesmo que «docere». Não parece ser outro o sentido das definições de "dialéctica» em Fonseca e no Curso Conimbricense, segundo os quais não deve apenas entender-se pela expressão «doctrina disserendi» que, como escreve Fonseca, "a dialéctica investiga a verdade discorrendo - pois isso é característico de todas as disciplinas —, mas que só ela ensina de que modo deve discorrer o espírito rectamente e sem erro, revelando o desconhecido com base naquilo que já se conhece». Ainda com maior exactidão, poderíamos dizer que a função da dialéctica é ensinar a ensinar. Este facto parece claro pelo lugar que nela ocupam as questões metodológicas. 
Deste modo, método e ensino, na perspectiva dos professores de Coimbra, são conceitos indissociáveis; inversamente, da ausência de método só pode resultar a confusão, quer ao nível dos espíritos, quer ao nível do objecto de cada ciência. Mas este ideal de ordem e de método não era exclusivo dos autores renascentistas. O Renascimento apenas acentuou, no domínio dos conteúdos do saber, uma forma mentis caracteristicamente medieval que estava reflectida na concepção cosmológica da perfeição e da harmonia do Universo. Nesta base, a prática do método nos planos de estudo e no ensino tinha como finalidade entre os nossos Jesuítas formar o espírito dos alunos, consciencializando-os de que um saber disperso e confuso é uma subversão da ordem natural das coisas.

Vistos nesta perspectiva, a obra lógica de Pedro da Fonseca e os Commentarii dos Conimbricenses manifestam uma característica de modernidade. E terá sido esse facto, ao menos em parte, que originou a sua enorme difusão. 



\section{Série}

\section{Documentos}

Imprensa da Universidade de Coimbra

Coimbra University Press

2007

- U

C • 